\title{
Comparative Analysis of Rheological Properties and Modification Mechanism of SBS-Graphene Composite Modified Binder
}

\author{
Jiangmiao YU ${ }^{1}$, Nikun YANG ${ }^{1}$, Huayang YU ${ }^{1 *}$, Svetlana Shekhovtsova ${ }^{2}$, Evgenii Korolev ${ }^{2}$ \\ 1 School of Civil Engineering and Transportation, South China University of Technology, Guangzhou, China \\ 2 Building materials and materials science, National Research Moscow State University of Civil Engineering, Moscow, Russia
}

*Corresponding Author: Huayang YU, Wushan Road, Tianhe District, Guangzhou 510000, China; huayangyu@scut.edu.cn

\begin{abstract}
:
SBS (styrene-butadiene-styrene block copolymer) has been widely used in pavement industry as an asphalt modifier. Nanomaterials can further enhance the performance of SBS modified asphalt. However, rare studies investigate the feasibility of using graphene as a performance enhancer of SBS modified asphalt. To fill this gap, comprehensive experimental tests including chemical and mechanical test were carried out on SBS-graphene modified asphalt and SEBS (styrene-ethylene-butylene-styrene block copolymer, which is a hydrogenated polymer of SBS) modified asphalt. Graphene with different dimensions and contents was taken into consideration in this study. Based on the experimental work, it can be concluded that graphene improves the mid-temperature performance of SBS modified asphalt. Compared with two-dimensional graphene, three-dimensional graphene has a greater advantage and the enhancement effect increases with the increase of its dosage. In addition, the cross-linked structure of SBS-graphene composite improves the distribution of SBS in asphalt, which improves the overall performance of SBS modified asphalt.
\end{abstract}

Keywords: SBS-graphene modified asphalt; chemical analysis; rheological properties

\section{Introduction}

Base asphalt, a pavement material, is prone to be defected such as rutting, cracking and aging, which limits its wide application in road construction. Modification of asphalt can significantly improve the performance of pavement. SBS (styrene-butadiene-styrene block copolymer) modified asphalt is widely used due to its high temperature stability and low temperature crack resistance. However, SBS is generally unevenly dispersed in the binder, which results in road surface damage of varying degrees under the multiple effects of long-term driving loads and natural factors ${ }^{[1-3]}$. In recent years, many studies have focused on the effect of unsaturated hydrogen bond content in SBS on asphalt pavement performance ${ }^{[4,5]}$. At the same time, it is widely reported that other nano materials are added to SBS modified asphalt to promote cross-linking between SBS and asphalt molecules and to improve the high temperature resistant rutting and low temperature cracking performance of asphalt pavement ${ }^{[6,7]}$.

SEBS (styrene-ethylene-butylene-styrene block copolymer) is a hydrogenated polymer of SBS, which is a linear tridoped copolymer with a polystyrene end segment and an ethylene-butene copolymer obtained by hydrogenating polybutadiene as an intermediate elastic block. SEBS does not contain unsaturated double bonds and therefore has good stability ${ }^{[8-10]}$.

Graphene is a monoatomic graphite layer. It is a honeycomb two-dimensional crystalline material that is infinitely extended by $\mathrm{sp}^{2}$ hybridized carbon atoms. Threedimensional graphene is composed of two-dimensional graphene and its porous structure gives it higher mechanical strength, electrical conductivity and specific surface area. Since its discovery in $2004^{[11]}$, graphene has attracted great attention from scientists, and researchers have reported its potential applications in electronics, energy storage and sensors. Each carbon atom in the graphene forms a covalent bond with the other three adjacent carbon atoms and the remaining one of the p-orbital electrons forms a $\pi$ bond, while the $\pi$ electron can move freely. These properties make it compatible with SBS and asphalt ${ }^{[12,13]}$. This unique structure that provides a large amount of electrons will be a potential bridge between asphalt and SBS compared to other inorganic nanomaterials ${ }^{[14,15]}$.

In this paper, SBS modified asphalt was used as the control group and the SBS-graphene modified asphalt and SEBS modified asphalt were comprehensively evaluated. In order to obtain better experimental results, SBS-graphene 
composite modifiers with different graphene contents were prepared by chemical coupling method. The modified asphalt is subjected to rheological and chemical tests respectively and the physical and rheological properties are characterized by including penetration, softening point, rutting factor, fatigue factor, etc. Gel permeation chromatography (GPC) analysis and Fourier transform infrared spectroscopy (FTIR) analysis were used to characterize the molecular weight distribution and chemical functional groups, revealing the composite modification mechanism of graphene-SBS modified asphalt.

\section{Materials and Methods}

\subsection{Materials}

In this study, the basic asphalt was suitable for Hong Kong with a penetration grade of 60/70 (Pen 60/70) and supplied by Xin Yue Transportation Technology Co., Ltd., Guangzhou. All graphene are supplied by GAC (Guangzhou Automobile Group Co., Ltd) Automotive Engineering Research Institute, including three-dimensional structure and two-dimensional structure. Among them, twodimensional graphene (2DG) is prepared from natural flake graphite by a simple redox method ${ }^{[12,13]}$. In detail, first, the nitric acid and the sulfuric acid are disposed in a certain proportion of the mixture and fully contacted with each layer of the graphite and the interlayer spacing of the graphite will increase with the generation of the gas to obtain the expanded graphite; then, the treated expanded graphite is placed in a strong oxidizing agent solution with a certain concentration and stored at a low temperature for a sufficient time; the residual oxidizing agent is removed by adding hydrogen peroxide, then the sample is moved to a vacuum drying oven for drying; finally, the sample was configured into a certain proportion of graphite oxide solution and sonicated to obtain a uniformly dispersed graphene oxide colloid and 2DG was obtained. Threedimensional graphene (3DG) is prepared by metal catalytic epitaxial growth ${ }^{[16,17]}$. Under ultra-high vacuum conditions, a certain amount of hydrocarbons are introduced into a catalytically active transition metal matrix (an alloy of copper and iron) and the 3DG is obtained by adsorbing a gas at a high temperature by catalytic dehydrogenation. The basic parameters of graphene are shown in Table 1.

SBS with linear structure was provided by Changzhou Lubis New Material Technology Co., Ltd, while SEBS was provided by Kraton Polymers, inc. SBS and SEBS are separately added to Pen $60 / 70$ as modifiers to further explore the differences before and after hydrogenation. At the same time, SBS and graphene are chemically coupled by $\mathrm{KH}-570$ (Silane Coupling Agent) at room temperature and dried to prepare SBS-graphene composite modifier. For the convenience of expression, the SBS-graphene composite modifiers prepared by different 2DG dosages are named 2DG-L and 2DG-H, respectively. The same method is used to prepare 3DG-L and 3DG-H. All modifiers are encoded and listed in Table 2.

Table 1. Basic parameters of graphene.

\begin{tabular}{cccccccc}
\hline & Layers & $\begin{array}{c}\text { Conductivity } \\
(\mathrm{S} / \mathrm{cm})\end{array}$ & $\begin{array}{c}\text { Bulk Density } \\
\left(\mathrm{g} / \mathrm{cm}^{3}\right)\end{array}$ & $\begin{array}{c}\text { Tap Density } \\
\left(\mathrm{g} / \mathrm{cm}^{3}\right)\end{array}$ & $\begin{array}{c}\text { Carbon Content } \\
(\mathrm{wt} \%)\end{array}$ & $\begin{array}{c}\text { Melting Point } \\
\left({ }^{\circ} \mathrm{C}\right)\end{array}$ & Exterior \\
\hline 2DG & $1-3$ & $450-700$ & $0.03-0.04$ & $0.05-0.06$ & $>98.5$ & $>3000$ & Gray-black powder \\
3DG & $5-10$ & $800-1300$ & $0.03-0.04$ & $0.04-0.05$ & $>95$ & $>3000$ & Black powder \\
\hline
\end{tabular}

Table 2. Modifier composition.

\begin{tabular}{|c|c|c|c|c|c|}
\hline \multirow{2}{*}{ Modifier Code } & \multicolumn{2}{|l|}{ Graphene Content } & \multirow{2}{*}{ SBS Content } & \multirow{2}{*}{ SEBS Content } & \multirow{2}{*}{ Hybrid Method } \\
\hline & Two-Dimensional & Three-Dimensional & & & \\
\hline SBS & - & - & $100.00 \mathrm{wt} \%$ & - & - \\
\hline SEBS & - & - & - & 100.00 wt $\%$ & - \\
\hline 2DG-L & $0.05 \mathrm{wt} \%$ & - & 99.95 wt $\%$ & - & \multirow{4}{*}{ Chemical coupling } \\
\hline 2DG-H & - & 0.10 wt $\%$ & 99.90 wt \% & - & \\
\hline 3DG-L & 0.05 wt $\%$ & - & 99.95 wt $\%$ & - & \\
\hline 3DG-H & - & 0.10 wt $\%$ & $99.90 \mathrm{wt} \%$ & - & \\
\hline
\end{tabular}

\subsection{Sample Preparation}

In order to gain the modified asphalts, high-speed shear mixer was utilized, whose purpose is to make the achievement about homogenous dispersion of the additives in the control asphalt. Considering the recommendation of manufacturer (GAC Automotive Engineering Research Institute), the modifier's dosages in this study are $4 \%$ by weight of asphalt. Here are the preparation processes listed as follows. (1) Heating control asphalt under the temperature of $170{ }^{\circ} \mathrm{C}$; then, adding modifier into the control asphalt and stirring them for 10 minutes. (2) Using high-speed shear mixer to mingle the modifier with asphalt at $160^{\circ} \mathrm{C}$ and $8000 \mathrm{rpm} / \mathrm{min}$ for an hour. The modifier code is used to represent the corresponding modified asphalt.

\subsection{Experiments}

\subsubsection{Standardized Performance Tests}

Supervised by the ASTM D5 and ASTM D36, penetration test at $25{ }^{\circ} \mathrm{C}$ and softening point quiz were conducted, separately. The former evaluates the asphalt binder's 
consistency, while the later estimates the binder performance at high service temperature. With the intention of determining the viscosities of modified asphalts with the temperature of 135,160 , and $165^{\circ} \mathrm{C}$, separately, the rotational viscometer (RV, RVDVII+, Brookfield Eng Labs Inc., Stoughton, MA, United States), which guided by AASHTO T316-13 method, was engaged.

A dynamic shear rheometer (DSR, Malvern instruments Inc., Santa Ana, CA, United States) was used in the different rheological tests. Superpave rutting factor $\left(\mathrm{G}^{*} / \sin \delta\right.$, for both unaged and RTFO aged samples) and non-recoverable creep compliance $\left(\mathrm{J}_{\mathrm{nr}}\right.$, for RTFO aged samples only), as two cardinal elements in high temperature performance, were utilized in order to adjudicate property. The Multi-stress Creep Recovery (MSCR) test is designed to determine Jnr in accordance with ASTM D7405. During the test, 10 cycles were carried out at stress levels of $0.1 \mathrm{KPa}$ and $3.2 \mathrm{KPa}$, respectively. In each test cycle, a creep load was applied for 1 second and recovered for 9 seconds.

The fatigue performance test was supervised on a Pressurized Aging Vessel (PAV) aged adhesive at a frequency of $10 \mathrm{rad} / \mathrm{s}$, which utilized the $8 \mathrm{~mm}$ diameter plates and $2 \mathrm{~mm}$ gap. The fatigue factor tests were started at $25^{\circ} \mathrm{C}$ with a decrement of $3^{\circ} \mathrm{C}$ until the fatigue factor was larger than $5000 \mathrm{KPa}$. In order to evaluate the fatigue properties of the asphalt adhesive, the fatigue resistance parameter $\left(\mathrm{G}^{*} \cdot \sin \delta\right)$ and failure temperature ( $\mathrm{T}$ fatigue) were employed. With regard to the linear amplitude sweep (LAS) test, PAV aged samples was also fit for this operation. At the LAS test, a frequency sweep was first performed followed by a linear amplitude strain sweep in order to make determination about the cycles to failure denoted as $\mathrm{N}_{\mathrm{f}}$. Then in the viscoelastic continuum damage (VECD) model, there is the fatigue failure's definition that is the $35 \%$ reduction of the initial modulus in the LAS test. There were three replicates prepared for each type of binder in these tests.

\subsubsection{Frequency Sweep}

Frequency sweeps in the linear viscoelastic range were measured at $4^{\circ} \mathrm{C}, 16^{\circ} \mathrm{C}, 28^{\circ} \mathrm{C}, 40^{\circ} \mathrm{C}, 52^{\circ} \mathrm{C}, 64^{\circ} \mathrm{C}$ and $76^{\circ} \mathrm{C}$, respectively, from $0.1(\mathrm{rad} / \mathrm{s})$ to $100(\mathrm{rad} / \mathrm{s})$ to evaluate the shear-deformation performance and temperature sensitivity of asphalt binders at the basis of timetemperature superposition principle. The parallel plates were prepped for the tests with diameter of $25 \mathrm{~mm}$ and gap of $1 \mathrm{~mm}$. In this test, one specimen was utilized.

\subsubsection{Chemical Tests}

The mechanism of adhesive was investigated by Gel Permeation Chromatography (GPC, Agilent 1260, Agilent Technologies Inc., California, USA) and Fourier transform infrared spectroscopy (FTIR, VERTEX 70, BRUKER, Germany). In order to assay the influences of graphene, SBS and SEBS on molecular weight distribution of asphalt liquid components in detail, GPC test was conducted and the infrared spectroscopy (FTIR) figured out the feature of chemical bonds and functional groups of asphalt. Two samples were used in here.

\section{Results and Discussion}

\subsection{Workability}

Table 3 shows the results of the penetration and softening point tests. The results clearly show that all modified asphalts have lower penetration and higher softening point than base asphalt, indicating that the SBS-graphene composite modifier and SEBS can make the asphalt more viscous and stable at high temperatures.

In detail, the penetration of all the modified asphalts was at the same level, the addition of graphene had no significant effect on the asphalt. Compared with SBS, all the graphene-added binders have a lower softening point, which mirrored the fact that the addition of graphene affects the high-temperature properties of SBS to some extent. Nevertheless, SEBS has a higher softening point and a slightly lower permeability than SBS, which signified that SEBS can make asphalt harder and more stable than SBS at high temperatures.

At the same time, the viscosity of modified asphalt at $135^{\circ} \mathrm{C}$ is much higher than that of pen $60 / 70$, but this may be the influence of polymers from the composition analysis of the modifier. It is worth noting that SEBS has a viscosity $20 \%$ higher than SBS at $135^{\circ} \mathrm{C}$. This is the fact that SEBS has a different compatibility with the light components in the bitumen after hydrogenation, which makes it easier to form a polymer network. Since the viscosity value of all modified asphalt is below $3000 \mathrm{cp}$, their mixture can be compacted at $160^{\circ} \mathrm{C}$, which is based on the AASHTO standard.

Table 3. Details of laboratory tests.

\begin{tabular}{llllll}
\hline \multirow{2}{*}{ Sample ID } & \multirow{2}{*}{ Penetration $(0.1 \mathrm{~mm})$} & softening point $\left({ }^{\circ} \mathrm{C}\right)$ & \multicolumn{4}{l}{ Rotational viscosity $(\mathrm{cP})$} \\
\cline { 4 - 6 } & & $47.9 \pm 0.2$ & $404.5 \pm 2.5$ & - & $160^{\circ} \mathrm{C}$ \\
\hline Pen60/70 & $64.5 \pm 1.4$ & $56.2 \pm 0.2$ & $1032.5 \pm 37.5$ & $357.5 \pm 12.5$ & $297.5 \pm 12.5$ \\
SBS & $44.0 \pm 0.9$ & $59.2 \pm 0.2$ & $1205.0 \pm 105.0$ & $417.5 \pm 42.0$ & $347.5 \pm 42.0$ \\
SEBS & $41.8 \pm 0.2$ & $54.6 \pm 0.2$ & $965.0 \pm 80.0$ & $330.0 \pm 20.0$ & $280.0 \pm 20.0$ \\
2DG-L & $44.3 \pm 0.4$ & $54.4 \pm 0.2$ & $962.5 \pm 72.5$ & $348.8 \pm 1.5$ & $288.8 \pm 1.5$ \\
2DG-H & $45.0 \pm 0.5$ & $54.3 \pm 0.1$ & $970.0 \pm 50.0$ & $338.8 \pm 1.0$ & $278.8 \pm 1.0$ \\
3DG-L & $43.0 \pm 0.9$ & $52.8 \pm 0.1$ & $995.0 \pm 75.0$ & $355.0 \pm 5.0$ & $285.0 \pm 5.0$ \\
3DG-H & $44.7 \pm 1.0$ & & & & \\
\hline
\end{tabular}

${ }^{1}$ The numbers after " \pm " are standard deviations. 


\subsection{Rutting Resistance}

The rutting factor test results for the binder is displayed in figure 1, which shows that all modifiers have a significant effect on improving rutting resistance. In the unaged state, SEBS has the highest destruction temperature. However, after a short period of aging, SBS's rutting performance is better than SEBS. Significantly, the rutting performance of SBS modified asphalt after aging is better than that before aging, while the rutting resistance of graphene added asphalt after aging is lower than that before aging, which proves that graphene is not conducive to rutting performance durability.

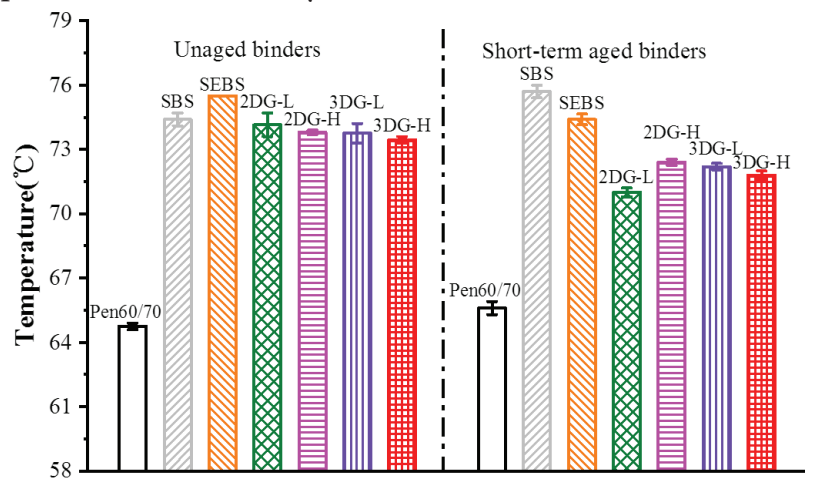

Figure 1. Rutting factor results.

Table 4 presents the MSCR test results. Drawing the conclusion that only the $\mathrm{J}_{\mathrm{nr}}$ difference of SEBS did not meet the requirement of AASHTO TP70-13 i.e., < 75\%. The reason is that the extremely low $\mathrm{J}_{\mathrm{nr}}$ values was applied at the stress of $0.1 \mathrm{kPa}{ }^{[18]}$. Based on the $\mathrm{J}_{\mathrm{nr}} 3.2$ values, Two- dimensional graphene and three-dimensional graphene had negative effects on rut resistance, while the rut resistance of SEBS was better than that of SBS. This is coherent with the results of rutting factor test before aging. Based on the $\mathrm{J}_{\mathrm{nr}} 0.1$ value, as the amount of graphene is increased, the rutting resistance of the binder is slightly enhanced, which indicates that graphene can make the asphalt harder. On the whole, under the same graphene content, the negative effect of two-dimensional graphene on rutting resistance was more significant.

\subsection{Fatigue Resistance}

The fatigue failure temperatures and the relationship between the $G^{*} \sin \delta$ value and the test temperature are illustrated in figure $2 \mathrm{a}$ and figure $2 \mathrm{~b}$, respectively. AASHTO M320 specified that the fatigue factor, $\mathrm{G}^{\star} \sin \delta$, should be less than $5 \mathrm{MPa}$ to pass a performance grade test at a specific temperature. As shown in the figure, there is a negative relationship between the fatigue failure temperature and fatigue resistance, that is, the higher the fatigue failure temperature is, the poorer the fatigue resistance the test binder has. As shown in figure $2 \mathrm{a}$, the fatigue failure temperature of SBS is $3.0^{\circ} \mathrm{C}$ higher than that of Pen60/70, which construes that SBS brings poor fatigue resistance, but graphene has a positive effect on the fatigue performance of SBS modified asphalt. The failure temperatures of 3DG-L and $3 \mathrm{DG}-\mathrm{H}$ are $0.3-0.5{ }^{\circ} \mathrm{C}$ lower than that of Pen60/70. In contrast, the failure temperatures of 2DG-L and 2DG-H are $1.5-2.0{ }^{\circ} \mathrm{C}$ higher than that of Pen60/70, which demonstrates that three-dimensional graphene has a superior fatigue resistance.

Table 4. MSCR test results.

\begin{tabular}{cccccc}
\hline \multirow{2}{*}{ Sample ID } & \multicolumn{3}{c}{$\mathrm{J}_{\mathrm{nr}}$} & \multicolumn{2}{c}{ \% Recovery } \\
\cline { 2 - 5 } & $0.1 \mathrm{kPa}(\mathrm{kPa}-1)$ & $3.2 \mathrm{kPa}(\mathrm{kPa}-1)$ & Jnr\% Diff & $0.1 \mathrm{kPa}(\mathrm{kPa}-1)$ & $3.2 \mathrm{kPa}(\mathrm{kPa}-1)$ \\
\hline Pen60/70 & $4.514 \pm 0.166$ & $5.007 \pm 0.154$ & $11.0 \pm 0.6$ & $0.7 \pm 0.4$ & $-0.5 \pm 0.2$ \\
SBS & $0.749 \pm 0.021$ & $1.162 \pm 0.036$ & $55.2 \pm 0.4$ & $31.5 \pm 0.6$ & $8.4 \pm 0.1$ \\
SEBS & $0.336 \pm 0.012$ & $0.906 \pm 0.088$ & $168.6 \pm 16.6$ & $65.7 \pm 1.8$ & $23.0 \pm 1.5$ \\
2DG-L & $1.132 \pm 0.009$ & $1.662 \pm 0.044$ & $46.9 \pm 3.4$ & $24.4 \pm 1.3$ & $3.8 \pm 0.3$ \\
2DG-H & $0.999 \pm 0.014$ & $1.523 \pm 0.016$ & $52.5 \pm 0.6$ & $28.6 \pm 0.2$ & $5.1 \pm 0.2$ \\
3DG-L & $0.952 \pm 0.011$ & $1.183 \pm 0.007$ & $24.2 \pm 0.7$ & $15.3 \pm 1.7$ & $4.0 \pm 0.1$ \\
3DG-H & $0.883 \pm 0.109$ & $1.253 \pm 0.055$ & $43.4 \pm 12.8$ & $19.4 \pm 5.3$ & $5.1 \pm 0.2$ \\
\hline
\end{tabular}

${ }^{1}$ The numbers after " \pm " are standard deviations.

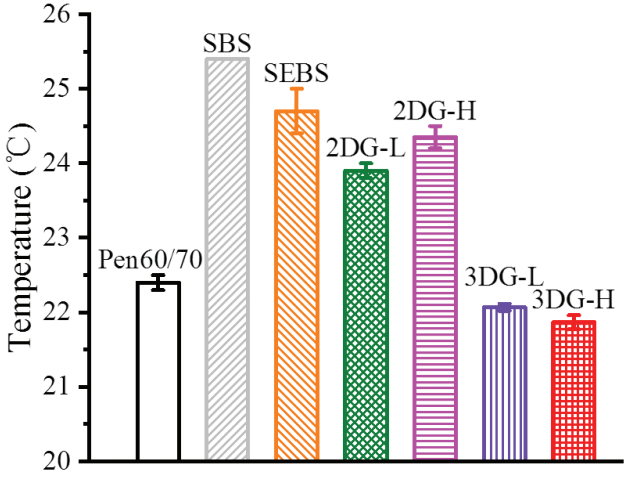

(a)

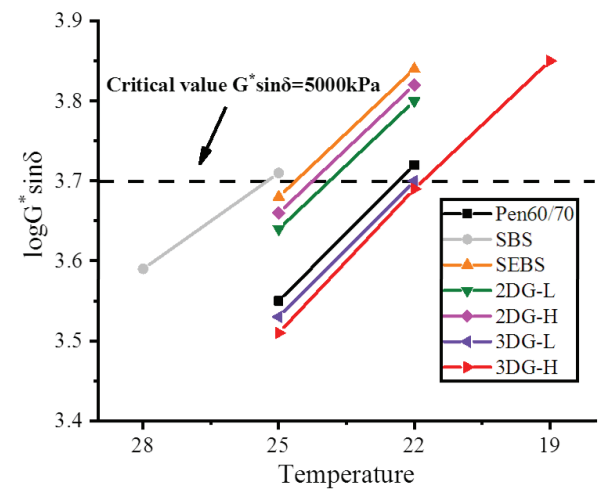

(b)

Figure 2. Fatigue performance of asphalt binders: (a) failure temperatures and (b) logarithm of $\mathrm{G}^{\star} \sin \delta$ values. 
Higher cycles to fatigue $\left(\mathrm{N}_{\mathrm{f}}\right)$ refer to better resistance of fatigue cracking. It can be seen from Table 5 that the $\mathrm{N}_{\mathrm{f}}$ value of all the modified asphalts is higher than that of the original asphalt at the strain levels of $2.5 \%$ and $5 \%$. Inconsistent with the fatigue factor results, all graphene have a negative impact on the fatigue properties of SBS in the LAS-based evaluation and increase with the increase in graphene content. Compared with SBS and SEBS, SEBS has better fatigue performance at higher strain levels and there is reason to believe that SEBS is more suitable for heavy traffic roads.

\subsection{Low Temperature Cracking Resistance}

Table 6 presents the consequence of the stiffness and $\mathrm{m}$-values of test binders under the test of BBR. There is an AASHTO T313 elaborating the criterion that the m-value should exceed 0.3 and the maximum of stiffness value is $300 \mathrm{MPa}$ at a certain temperature level. The effect on low-temperature cracking is higher stiffness value. Table 6 shows that 2DG plays a positive role in the lowtemperature properties of asphalt, but this positive effect will be weakened with the increase of the content of the 2DG; significantly, the lower content of 3DG has a negative effect on the asphalt's low-temperature. With the increase of the content of 3DG, the negative effect will turn into a positive; the stiffness value of SEBS is markedly higher than that of SBS, which meets the requirements that SEBS is harder. It can be seen that graphene has a positive effect on the low temperature performance of adhesives, and with the same amount of graphene, the improvement of the low temperature performance of two-dimensional graphene is better than that of three-dimensional graphene.

Table 5. LAS test results.

\begin{tabular}{ccc}
\hline \multirow{2}{*}{ Sample ID } & \multicolumn{2}{c}{$\mathrm{N}_{\mathrm{f}}$} \\
\cline { 2 - 3 } & Applied Strain of $2.5 \%$ & Applied Strain of $5.0 \%$ \\
\hline Pen60/70 & $17926 \pm 39$ & $2236 \pm 55$ \\
SBS & $66681 \pm 1544$ & $5060 \pm 138$ \\
SEBS & $56078 \pm 1149$ & $5294 \pm 130$ \\
2DG-L & $51548 \pm 742$ & $5017 \pm 48$ \\
2DG-H & $38357 \pm 1764$ & $3832 \pm 268$ \\
3DG-L & $36840 \pm 2550$ & $4388 \pm 295$ \\
3DG-H & $30451 \pm 870$ & $3755 \pm 124$ \\
\hline
\end{tabular}

${ }^{1}$ The numbers after “ \pm ” are standard deviations.

Table 6. BBR test results.

\begin{tabular}{lllll}
\hline \multirow{2}{*}{ Sample ID } & $-12^{\circ} \mathrm{C}$ & \multicolumn{3}{c}{$-18^{\circ} \mathrm{C}$} \\
\cline { 2 - 5 } & Stiffness $(\mathrm{MPa})$ & $\mathrm{m}$-value $(\times 10-2)$ & Stiffness $(\mathrm{MPa})$ & $\mathrm{m}$-value $(\times 10-2)$ \\
\hline SBS & $244.0 \pm 9.9$ & $35.0 \pm 2.8$ & $390.0 \pm 25.5$ & $31.0 \pm 1.4$ \\
SEBS & $314.0 \pm 8.5$ & $27.5 \pm 3.5$ & $498.5 \pm 3.5$ & $20.0 \pm 0.0$ \\
2DG-L & $225.5 \pm 7.8$ & $38.0 \pm 1.4$ & $372.0 \pm 4.2$ & $29.0 \pm 2.8$ \\
2DG-H & $251.5 \pm 19.1$ & $38.0 \pm 0.0$ & $389.5 \pm 3.5$ & $30.5 \pm 0.7$ \\
3DG-L & $250.5 \pm 7.8$ & $33.0 \pm 0.0$ & $400.5 \pm 16.3$ & $18.0 \pm 0.0$ \\
3DG-H & $235.0 \pm 2.8$ & $32.5 \pm 0.7$ & $377.5 \pm 10.6$ & $24.5 \pm 3.5$ \\
\hline
\end{tabular}

${ }^{1}$ The numbers after " \pm " are standard deviations.

\subsection{Overall Rheological Behavior}

The main curve (reference temperature: $60^{\circ} \mathrm{C}$ ) was obtained over a series of frequency sweeps with various frequencies between 0.01 and $30 \mathrm{~Hz}$ and ranged the temperature from 76 to $4{ }^{\circ} \mathrm{C}$. The best fit of the frequency sweep test data is performed in order to obtain a single master curve. The single master curve is based on the Williams-LandelFerry (WLF) formula (Equation 1 and Equation 2) and the S-shaped function (Equation 3).

$\log (\mathrm{a}(\mathrm{T}))=\frac{-C_{1} \Delta T}{C_{2}+\Delta T}$

where $\mathrm{a}(\mathrm{T})$ is the shift factor at a particular temperature $\mathrm{T}, \Delta \mathrm{T}$ is the difference between the quiz temperature and reference temperature and $\mathrm{C}_{1}$ and $\mathrm{C}_{2}$ are model constants. $\log (\xi)=\log (f)+\log (\mathrm{a}(\mathrm{T}))$

where $\xi$ is the frequency of decrease at reference temperature and $\mathrm{f}$ is the test frequency at a particular temperature.

$\log \left(\mathrm{G}^{*}\right)=\delta+\frac{\alpha}{1+e^{\beta+\gamma \log (\xi)}}$

where $\beta, \gamma$ are the shape parameters, $\alpha$ is the span of $G^{*}$ values and $\delta$ is the minimum modulus value.

In order to obtain the main curve, an evaluation function about the overall rheological properties of asphalt adhesive at wide angle frequencies $\left(10^{-2}-10^{-8} \mathrm{~Hz}\right)$, a series of complicated mathematical calculations were performed. First, the WLF formula (Equation 1 and Equation 2) is substituted into the sigmoid function (Equation 3), then 
gain the (Equation 4).

$$
\log \left(\mathrm{G}^{*}\right)=\delta+\frac{\alpha}{1+e^{\beta+\gamma\left(\log (f)+\frac{-C_{1} \Delta T}{C_{2}+\Delta T}\right)}}
$$

A nonlinear surface fit is then performed using (Equation 4) to acquire parameters $\mathrm{C}_{1}$ and $\mathrm{C}_{2}$, with $\log (\mathrm{f})$ and $\Delta \mathrm{T}$ as independent variables. A different loading frequency is moved at a given temperature $\left(60{ }^{\circ} \mathrm{C}\right)$ to attain a single master curve based on (Equation 2). Finally, the fitted master curve is obtained by best fit based on (Equation 3). The parameters of the WLF formula and the sigmoidal function are shown in Table 7.

Figure 3 is a main curve of the test adhesive $\mathrm{G}^{*}$ at a reference temperature of $60{ }^{\circ} \mathrm{C}$. Based on the sigmoidal function, the scattering and smooth curves of $\lg \left|\mathrm{G}^{*}\right|$ and down-conversion $\left(\operatorname{lgf}_{\mathrm{r}}\right)$ are obtained. According to the principle of time-temperature superposition of viscoelastic materials, the low frequency is high temperature and vice versa. As expected, the increase in frequency results in an increase in the complex shear modulus. It can be seen from figure $3 \mathrm{~b}$ that the modulus of all modified asphalts is lower at high frequencies and higher at low frequencies than pure asphalt, which indicates that modifiers has better performance at both high and low temperatures. Furthermore, it can be clearly seen that the performance increase at low frequencies is higher than that at high frequencies. At the same time, the performance order in the low frequency state is $\mathrm{SEBS}>3 \mathrm{DG}-\mathrm{L}>3 \mathrm{DG}-\mathrm{H}=2 \mathrm{DG}-$ $\mathrm{L}>2 \mathrm{DG}-\mathrm{H}>\mathrm{SBS}$, which elucidates that the incorporation of graphene is beneficial to improve the high temperature performance of binders and the three-dimensional graphene is better than two-dimensional graphene.

Table 7. Model parameters of the WLF formula and sigmoidal function.

\begin{tabular}{cccccccc}
\hline \multirow{2}{*}{ Parameters } & \multicolumn{3}{c}{ WLF Formula } & \multicolumn{5}{c}{ Sigmoidal Function } \\
\cline { 2 - 7 } & $C_{I}(-)$ & $C_{2}(-)$ & $\delta(\mathrm{Pa})$ & $\alpha(\mathrm{Pa})$ & $\mathrm{B}(-)$ & $\gamma(-)$ & $\mathrm{R}^{2} @\left|\mathrm{G}^{*}\right|(-)$ \\
\hline Pen60/70 & -8.99089 & 140.61166 & -7.22452 & 8.50196 & 0.29137 & 0.46757 & 0.99937 \\
SBS & -7.92734 & 128.67858 & -6.88191 & 8.13285 & 0.28951 & -0.43905 & 0.99953 \\
SEBS & -7.95639 & 128.89044 & -6.09833 & 7.28080 & 0.49296 & -0.47701 & 0.99958 \\
2DG-L & -7.97217 & 129.20746 & -6.4882 & 7.64965 & 0.37949 & -0.46618 & 0.99957 \\
2DG-H & -7.94625 & 129.19929 & -6.61167 & 7.82445 & 0.37393 & -0.45369 & 0.99954 \\
3DG-L & -8.09145 & 130.34157 & -6.32974 & 7.53926 & 0.43375 & -0.46519 & 0.99951 \\
3DG-H & -7.93549 & 130.50466 & -6.39626 & 7.55406 & 0.40649 & -0.48011 & 0.99973 \\
\hline
\end{tabular}

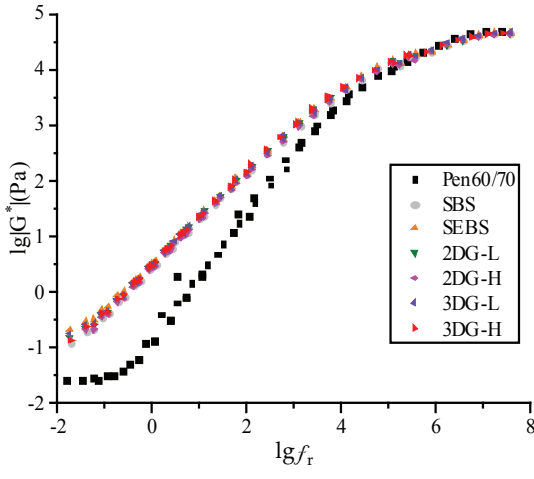

(a)

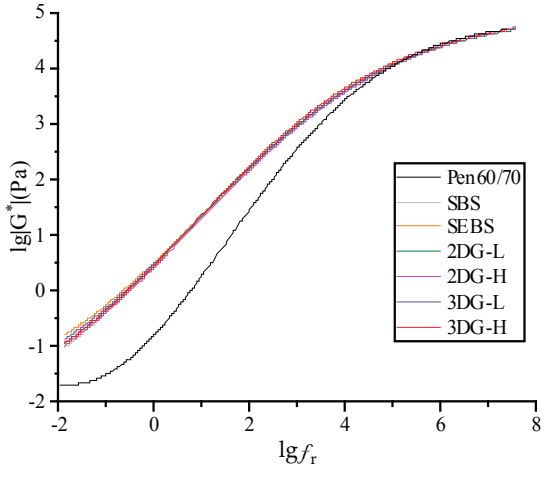

(b)

Figure 3. Master curves of test binders: (a) scatters of test results and (b) sigmoidal fitting curves.

\subsection{Molecular Weight Distribution}

Figure 4 is a GPC test result of the test adhesive. By analyzing the fluctuation curve of the test adhesive, the elution amount in a specific molecular range can be obtained ${ }^{[19-22]}$. It is clear that the GPC test results for all adhesives have two peaks and the two peaks are plotted separately for ease of description. As shown in figure $4 \mathrm{~b}$ and figure $4 \mathrm{c}$, a chromatogram with a retention time of $10.9 \sim 18.0$ minutes (molecular weight $22549 \mathrm{~g} / \mathrm{mol} \sim 125$ $\mathrm{g} / \mathrm{mol}$ ) and $9.17 \sim 9.71$ minutes (molecular weight $79671 \mathrm{~g} /$ $\mathrm{mol} \sim 53749 \mathrm{~g} / \mathrm{mol}$ ) was selected and disjoint them into 8 parts on average. The entire area of the eight samples was adjusted to 1 , then their area ratios and molecular weight distributions were compared. A higher area ratio represents a larger percentage of a particular molecular size.

Figure $4 \mathrm{~b}$ shows molecular weights ranging from $22549 \mathrm{~g} / \mathrm{mol}$ to $125 \mathrm{~g} / \mathrm{mol}$. The components here are mainly asphalt macromolecules. In the range of $16.3 \sim 18.0 \mathrm{~min}$, the proportion of SBS is lower than other modified asphalt. This may be the effect of graphene on other binders. Figure $4 \mathrm{c}$ shows molecular weights ranging from $79771 \mathrm{~g} / \mathrm{mol}$ to $53749 \mathrm{~g} / \mathrm{mol}$. The main component here is a polymer macromolecule (SBS or SEBS). On the basis of SBS modified asphalt, graphene moves the peaks of other binders to the left, which proves that the chemical coupling treatment of graphene and SBS has certain effects. It should be specially 
pointed out that the peak shift of 3DG-L and 3DG-H to the left is significant, which indicates that there is a better coupling mechanism between the three-dimensional structure of graphene and SBS.

The GPC test results is listed in Table 8 which is based on numerical statistics analysis. Five different parameters were selected for the purpose of understanding the situation of the variations of molecular weight distribution during the modification process, i.e. peak molecular weight (Mp), number-average molecular weight $(\mathrm{Mn})$, weightaverage molecular weight $(\mathrm{Mw})$, polydispersity (PDI = $\mathrm{Mw} / \mathrm{Mn}$ ) and area ratio (Area). The main component of Peak1 is asphalt and the PDI value of $2 \mathrm{DG}-\mathrm{H}$ is higher than
2DG-L, showing that the molecular weight distribution of $2 \mathrm{DG}-\mathrm{H}$ is more dispersed. The PDI value of $3 \mathrm{DG}-\mathrm{H}$ was lower than that of $3 \mathrm{DG}-\mathrm{L}$, indicating that the molecular weight distribution of 3DG-H was more concentrated. The main component of Peak2 is SBS modifier. The Mw values of 3DG-L and 3DG-H are significantly larger than other binders, that is to say, $3 \mathrm{D}$ graphene may establish a better coupling mechanism with SBS modifier. From the aspect of area ratio, the area ratio of Peak 2 decreased with the increase of graphene content, which substantiates that graphene would contribute to the dissolution of SBS. At the same time, 2DG makes SBS dissolution better than 3DG.



(a)

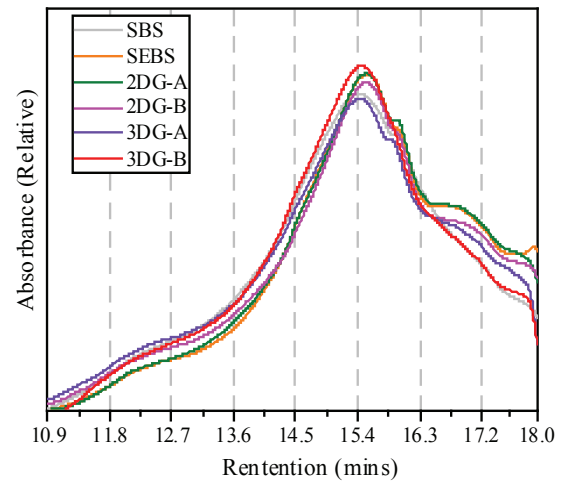

(b)



(c)

Figure 4. GPC test results: (a) chromatograms of test binders (all the range), (b) chromatograms of test binders (from 10.9 to 18.0 mins), and (c) chromatograms of test binders (from 9.17 to $9.71 \mathrm{mins}$ )

Table 8. GPC parameters.

\begin{tabular}{|c|c|c|c|c|c|c|}
\hline Sample ID & & $\mathrm{Mp}(\mathrm{g} / \mathrm{mol})$ & $\mathrm{Mn}(\mathrm{g} / \mathrm{mol})$ & $\mathrm{Mw}(\mathrm{g} / \mathrm{mol})$ & PDI (-) & Area (\%) \\
\hline \multirow{2}{*}{ SBS } & Peak 1 & $804 \pm 2$ & $522 \pm 36$ & $1648 \pm 86$ & $3.1636 \pm 0.0504$ & 98.3267 \\
\hline & Peak 2 & $67759 \pm 0$ & $64497 \pm 586$ & $65191 \pm 380$ & $1.0108 \pm 0.0033$ & 1.67328 \\
\hline \multirow{2}{*}{ SEBS } & Peak 1 & $763 \pm 0$ & $480 \pm 19$ & $1495 \pm 97$ & $3.1105 \pm 0.0779$ & 98.4319 \\
\hline & Peak 2 & $67938 \pm 1$ & $65251 \pm 360$ & $65870 \pm 293$ & $1.0095 \pm 0.0011$ & 1.5681 \\
\hline \multirow{2}{*}{ 2DG-L } & Peak 1 & $758 \pm 1$ & $409 \pm 67$ & $1302 \pm 108$ & $3.2288 \pm 0.2625$ & 98.4314 \\
\hline & Peak 2 & $68297 \pm 1$ & $64727 \pm 793$ & $65587 \pm 742$ & $1.0133 \pm 0.0009$ & 1.56858 \\
\hline \multirow{2}{*}{ 2DG-H } & Peak 1 & $776 \pm 9$ & $490 \pm 2$ & $1600 \pm 116$ & $3.2669 \pm 0.2259$ & 98.8424 \\
\hline & Peak 2 & $68478 \pm 3$ & $64940 \pm 542$ & $65596 \pm 397$ & $1.0101 \pm 0.0023$ & 1.15764 \\
\hline \multirow{2}{*}{ 3DG-L } & Peak 1 & $827 \pm 5$ & $548 \pm 3$ & $1810 \pm 138$ & $3.3016 \pm 0.2338$ & 98.4327 \\
\hline & Peak 2 & $70489 \pm 1$ & $66843 \pm 1095$ & $67542 \pm 958$ & $1.0105 \pm 0.0022$ & 1.56733 \\
\hline \multirow{2}{*}{ 3DG-H } & Peak 1 & $807 \pm 2$ & $545 \pm 23$ & $1609 \pm 44$ & $2.9541 \pm 0.0439$ & 98.4945 \\
\hline & Peak 2 & $70119 \pm 1$ & $66435 \pm 783$ & $67284 \pm 526$ & $1.0128 \pm 0.0040$ & 1.50547 \\
\hline
\end{tabular}

1 The numbers after " \pm " are standard deviations. 


\subsection{Chemical Bonds Variation}

Figure 5a-g present the FTIR spectra of all binders, respectively. Similar spectra of FTIR indicates their close chemical components ${ }^{[23]}$. Figure 5a-c shows the FTIR spectra of base asphalt, SBS and SEBS, respectively, and the spectra of the three show similar peaks. They are all at $2854 \mathrm{~cm}^{-1}$ (symmetric stretching vibration of $-\mathrm{CH} 2-$ ), $1601 \mathrm{~cm}^{-1}$ (C=C stretching vibration), $1376 \mathrm{~cm}^{-1}$ (symmetric deformation vibration of $-\mathrm{CH} 3), 750 \mathrm{~cm}^{-1}$ (=CH out-ofplane deformation of single substituted benzene ring) reaches the peak. SBS and SEBS did not peak at $724 \mathrm{~cm}^{-1}$
$(-(\mathrm{CH} 2) n$ - rocking vibration of alkane groups, $\mathrm{n}>4)$. This may lead to a smaller average molecular weight than neat bitumen. Whether it is base asphalt or SBS modified asphalt, the maximum peaks appear at 2920 and $1460 \mathrm{~cm}^{-1}$ respectively, wherein the peak at $2920 \mathrm{~cm}^{-1}$ corresponds to the stretching vibration of the $\mathrm{C}-\mathrm{H}$ and the deformation vibration at the $1460 \mathrm{~cm}^{-1}$ corresponds to the $\mathrm{C}-\mathrm{H}$, indicating that whether in the matrix asphalt or in the SBS modified asphalt, the $\mathrm{CH}$ bond is still the main body, which is consistent with the small amount of SBS or SEBS.

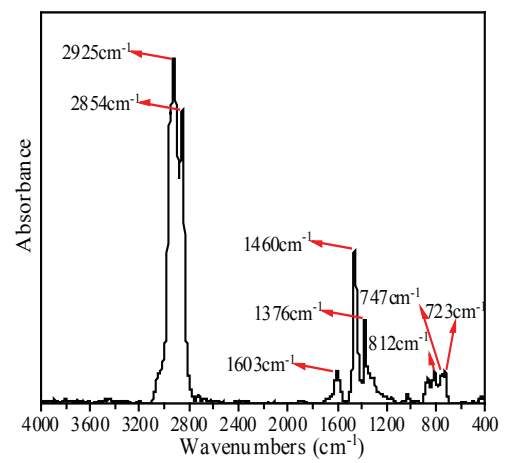

(a)

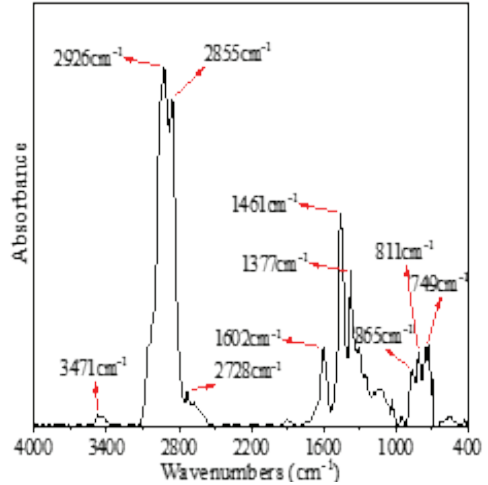

(d)

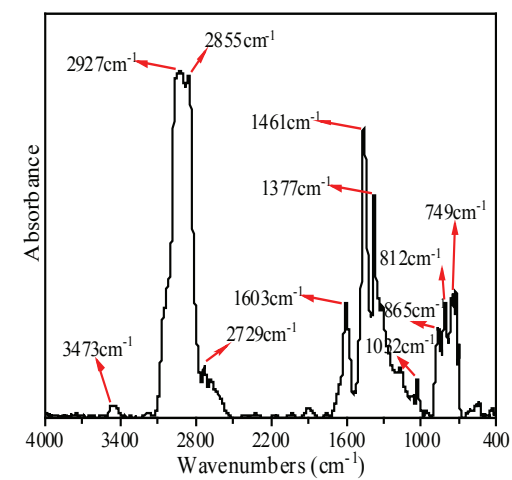

(f)

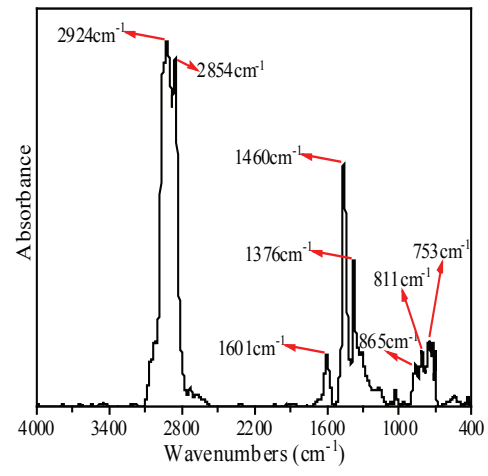

(b)

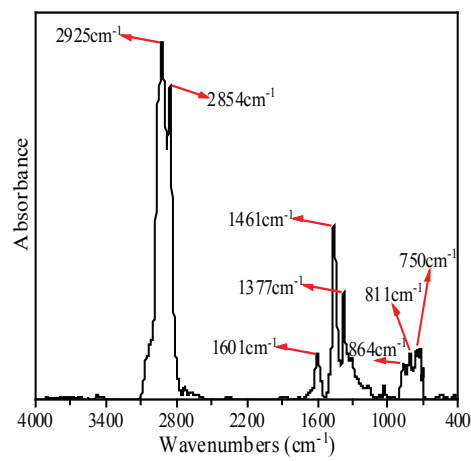

(c)

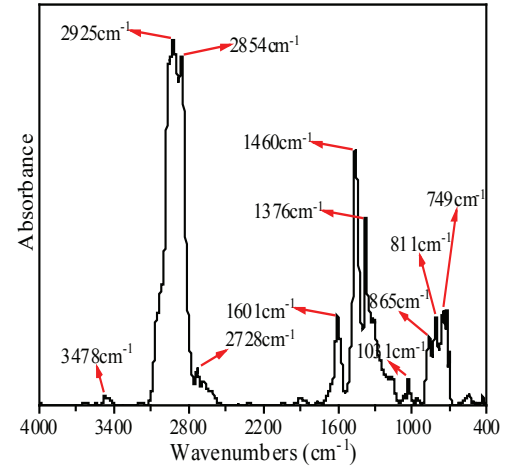

(e)

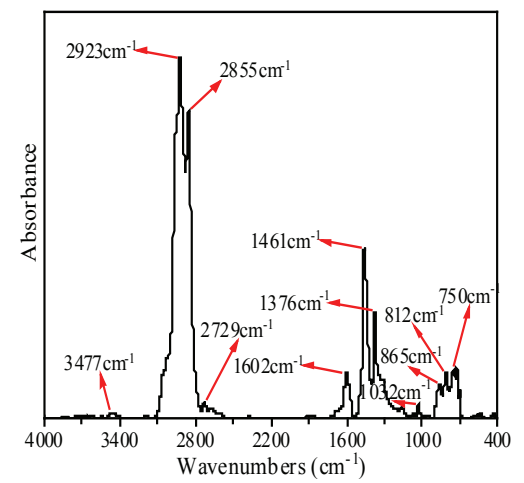

(g)

Figure 5. FTIR test results: (a) Base binder, (b) SBS, (c) SEBS, (d) 2DG-L, (e) 2DG-H, (f) 3DG-L, and (g) 3DG-H. (They're all spectra of the binders)

Figure 5d-g shows the FTIR spectrum of grapheneSBS composite modified asphalt. All spectra have a wide range of $3470 \mathrm{~cm}^{-1}(-\mathrm{OH}$ or $-\mathrm{NH}$ stretching vibration of hydrogen-bonded hydroxyl group and amino groups). Binders also reached a peak near $2730 \mathrm{~cm}^{-1}$, which was caused by the $\mathrm{C}-\mathrm{H}$ stretching vibration in - $\mathrm{CHO}$, but not in SBS and SEBS. Since there is no oxygen element in SBS, it can be speculated that oxygen element comes from the residue during the preparation of graphene.

Figure 6 shows the micro-morphology of all modifiers 
under the scanning electron microscope (SEM, Merlin, Zeiss Inc., Germany). In fact, because the SBS/SEBS particles are not at the nanoscale, the amplification of the sample is too large to get an effective and clear image, so the maximum amplification of the experimental control is 50,000 times. Figure $6 \mathrm{a}-\mathrm{c}$ present that SEBS has a rougher appearance and a larger specific surface area than SBS, which will help to fully contact the asphalt during the binder preparation process. Under chemical coupling, twodimensional graphene and three-dimensional graphene are well connected with SBS. Figure 6d shows that the two-dimensional graphene appears in a sheet shape and is covered on the SBS. Figure 6e shows that the threedimensional graphene is embedded in the graphene surface in a block shape. It can be inferred that three-dimensional graphene and SBS have a better connection effect compared with two-dimensional graphene, which is consistent with the GPC test results.

The mechanism of the graphene-SBS composite modifier which contributes to the asphalt modification can be explained as follows. In the modification process by high shear mixing, chemical bonding and physical absorption may result in redistribution of hydrocarbon chains. A more compact and more stable microstructure is then obtained.

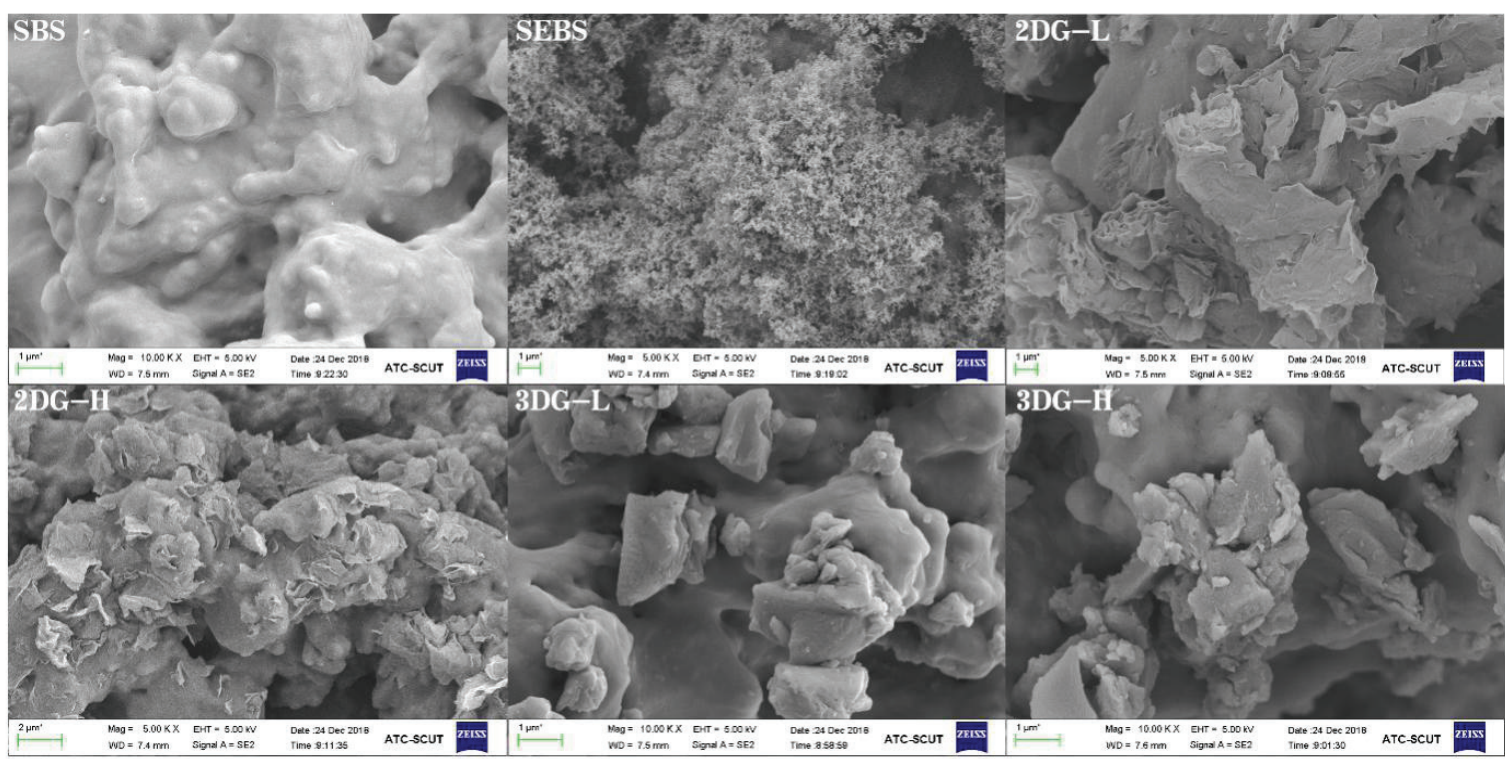

(a)

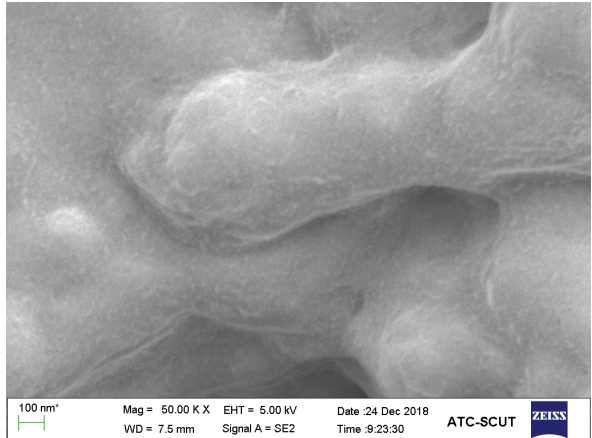

(b)

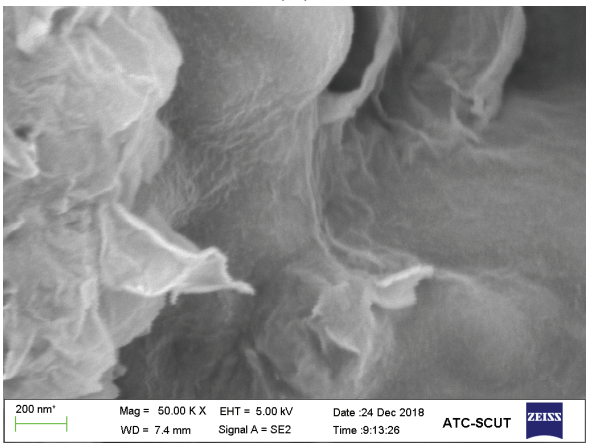

(d)

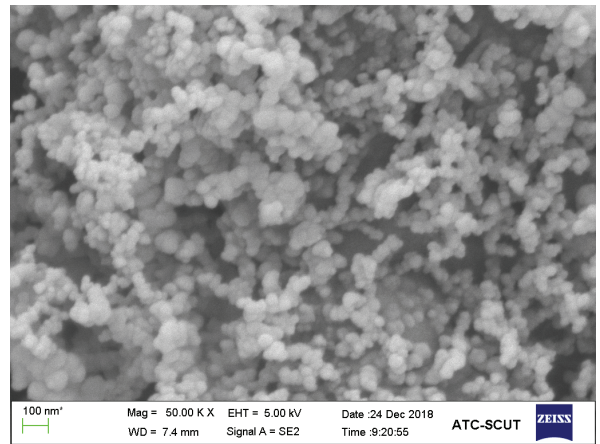

(c)

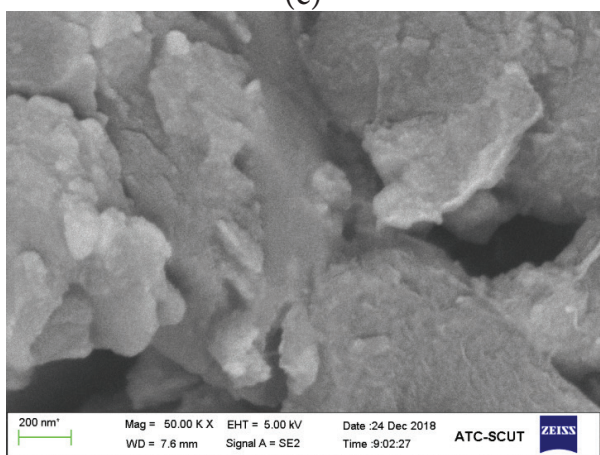

(e)

Figure 6. SEM results: (a) Microscopic morphology of all modifiers, (b) Pure SBS, (c) Pure SEBS, (d) 2D grapheneSBS composite modifier, and (e) 3D graphene-SBS composite modifier. 


\section{Conclusions}

This study investigated the feasibility of using graphene as a performance enhancer for SBS modified asphalt. Effects of different dimensions and different amounts of graphene on the performance of SBS modified asphalt were comprehensively evaluated using rheological and chemical experiments. In addition, SEBS and SBS modified asphalt was prepared and selected as control groups. Based on the test results, the following were found.

Graphene has limited negative impacts on rutting resistance and fatigue resistance.

There are significant enhancements on the intermediate temperature properties of graphene-SBS modified asphalt. The improvement in asphalt modified by three-dimensional graphene and SBS is particularly remarkable.

Two-dimensional graphene modified SBS asphalt reports better low temperature performance in comparison with control groups.

Because SEBS has a more stable structure (SEBS contains no unsaturated double bonds), SEBS modified asphalt has better rutting performance and fatigue resistance than that of SBS modified asphalt.

Graphene, especially three-dimensional graphene, can establish a good connection with SBS through chemical coupling, besides graphene helps SBS dissolve to a limited extent, resulting in a more uniform binder.

Author Contributions: Data curation, N.Y. Funding acquisition, J.Y. Investigation, S.S., E.K., J.Y., and H.Y. Methodology, J.Y., S.S., E.K., and H.Y. Supervision, J.Y. Writing_original draft, N.Y. Writing_review \& editing, H.Y.

Conflict of Interest: The authors declare that there is no conflict of interest regarding the publication of this paper.

Acknowledgments: The authors sincerely acknowledge the funding support from National Natural Science Foundation of China (51678251) and Central University's Basic Research Business Fees Transformation and Cultivation Project (2018KZ001). Trademark or manufacturers' names appear in this paper only because they are considered essential to the object of this paper.

\section{References}

[1] Zhang, W., Z. Jia, Y. Zhang, K. Hu, L. Ding, and F. Wang. The Effect of Direct-to-Plant Styrene-Butadiene-Styrene Block Copolymer Components on Bitumen Modification. Polymers, Vol. 11, No. 1, 2019.

[2] Li, Y., S. Wu, L. Pang, Q. Liu, Z. Wang, and A. Zhang. Investigation of the Effect of Mg-Al-LDH on Pavement Performance and Aging Resistance of StyreneButadiene-Styrene Modified Asphalt. Construction and Building Materials, Vol. 172, 2018, pp. 584-596.

[3] Yan, C., F. Xiao, W. Huang, and Q. Lv. Critical Matters in
Using Attenuated Total Reflectance Fourier Transform Infrared to Characterize the Polymer Degradation in Styrene-Butadiene-Styrene-Modified Asphalt Binders. Polymer Testing, Vol. 70, 2018, pp. 289-296.

[4] Cao Qingxia, He zhaoyi, L. Overview of SBS Modified Asphalt Aging Research. Polymer Materials Science\&Engineering, Vol. 27, 2013, pp. 1-5.

[5] Gao, Y., F. Gu, and Y. Zhao. Thermal Oxidative Aging Characterization of SBS Modified Asphalt. Journal Wuhan University of Technology, Materials Science Edition, Vol. 28, No. 1, 2013, pp. 88-91.

[6] Rooholamini, H., R. Imaninasab, and M. Vamegh. Experimental Analysis of the Influence of SBS/Nanoclay Addition on Asphalt Fatigue and Thermal Performance. International Journal of Pavement Engineering, Vol. 20, No. 6, 2019, pp. 628-637.

[7] Zhang, D., Z. Chen, H. Zhang, and C. Wei. Rheological and Anti-Aging Performance of SBS Modified Asphalt Binders with Different Multi-Dimensional Nanomaterials. Construction and Building Materials, Vol. 188, 2018, pp. 409-416.

[8] Zhang, F., C. Hu, and Y. Zhang. Research for SEBS / PPA Compound-Modified Asphalt. Journal of Applied Polymer Science, Vol. 46085, 2018, pp. 1-10.

[9] Ma Feng, Yang Tiantian, Fu Zhen, X. H. Overview of SEBS Modified Asphalt. Petroleum Asphalt, Vol. 32, 2018, pp. 2-6.

[10] Zapién-castillo, S., J. L. Rivera-armenta, M. Y. Chávezcinco, B. A. Salazar-cruz, and A. M. Mendoza-martínez. Physical and Rheological Properties of Asphalt Modified with SEBS / Montmorillonite Nanocomposite. Vol. 106, 2016, pp. 349-356.

[11] Raimond, J. M., M. Brune, Q. Computation, F. De Martini, and C. Monroe. Electric Field Effect in Atomically Thin Carbon Films. Vol. 306, No. October, 2004, pp. 666-670.

[12] Allen, M. J., V. C. Tung, and R. B. Kaner. Honeycomb Carbon: A Review of Graphene. 2010, pp. 132-145.

[13] Choi, W., I. Lahiri, R. Seelaboyina, Y. S. Kang, W. Choi, I. Lahiri, and R. Seelaboyina. Synthesis of Graphene and Its Applications: A Review Synthesis of Graphene and Its Applications: A Review. Vol. 8436, 2010.

[14] Du, H., and S. D. Pang. Enhancement of Barrier Properties of Cement Mortar with Graphene Nanoplatelet. Cement and Concrete Research, Vol. 76, 2015, pp. 10-19.

[15] Du, H., and S. D. Pang. Mechanical Response and Strain Sensing of Cement Composites Added with Graphene Nanoplatelet Under Tension. Nanotechnology in construction, 2015, pp. 377-382.

[16] Cao, X., B. Zheng, X. Rui, W. Shi, Q. Yan, and H. Zhang. Metal Oxide-Coated Three-Dimensional Graphene Prepared by the Use of Metal-Organic Frameworks as Precursors**. Angewandte Chemie - International Edition, Vol. 53, No. 5, 2014, pp. 1404-1409. 
[17] Wen, X., D. Zhang, T. Yan, J. Zhang, and L. Shi. ThreeDimensional Graphene-Based Hierarchically Porous Carbon Composites Prepared by a Dual-Template Strategy for Capacitive Deionizationt. Journal of Materials Chemistry A, Vol. 1, No. 39, 2013, pp. 1233412344.

[18] Yu, H., Z. Leng, F. Xiao, and Z. Gao. Rheological and Chemical Characteristics of Rubberized Binders with Non-Foaming Warm Mix Additives. Construction and Building Materials, Vol. 111, 2016, pp. 671-678.

[19] Ding, Y., B. Huang, and X. Shu. Investigation of Functional Group Distribution of Asphalt Using Liquid Chromatography Transform and Prediction of Molecular Model. Fuel, Vol. 227, No. April, 2018, pp. 300-306.

[20] Wang, D., D. Li, J. Yan, Z. Leng, Y. Wu, J. Yu, and H. Yu. Rheological and Chemical Characteristic of Warm Asphalt Rubber Binders and Their Liquid Phases. Construction and Building Materials, Vol. 193, 2018, pp.
547-556.

[21] Yang, S. H., and L. C. Lee. Characterizing the Chemical and Rheological Properties of Severely Aged Reclaimed Asphalt Pavement Materials with High Recycling Rate. Construction and Building Materials, Vol. 111, 2016, pp. 139-146.

[22] Kim, S., S. H. Lee, O. Kwon, J. Y. Han, Y. S. Kim, and K. W. Kim. Estimation of Service-Life Reduction of Asphalt Pavement Due to Short-Term Ageing Measured by GPC from Asphalt Mixture. Road Materials and Pavement Design, Vol. 17, No. 1, 2016, pp. 153-167.

[23] Fini, E. H., D. J. Oldham, and T. Abu-Lebdeh. Synthesis and Characterization of Biomodified Rubber Asphalt: Sustainable Waste Management Solution for Scrap Tire and Swine Manure. Journal of Environmental Engineering (United States), Vol. 139, No. 12, 2013, pp. 1454-1461. 